\title{
A OBRA POLISSÊMICA DE MICHAEL LÖWY
}

\section{INTRODUÇÃO}

\author{
Ricardo Antunes* \\ Ricardo Festi ${ }^{* *}$ \\ Fabio Querido***
}

\section{INTRODUÇÃO}

Nascido no Brasil, filho de pais judeus austríacos, francês por opção existencial, Michael Löwy (1938-) é um intelectual singular. À beira de oito décadas de uma vida muito bem vivida, marcadas sempre por uma intensa atividade intelectual e política, Löwy é responsável por uma trajetória cuja magnitude contabiliza cerca de trinta livros publicados em distintos países e de uma originalidade que lhe permite oferecer sempre um novo olhar sobre novas questões (mesmo aquelas que pareciam já "superadas"), o que tornou sua obra reconhecida internacionalmente (Delecroix; Dianteill, 2011). ${ }^{1}$

\footnotetext{
* Universidade Estadual Paulista (Unicamp). Departamento de Sociologia.

Rua Cora Coralina, 100. Cidade Universitária. Cep: 13083-896. Campinas - São Paulo - Brasil. rlcantunes53@gmail.com

${ }^{* *}$ Universidade Estadual Paulista (Unicamp). Departamento de Humanas do COTIL.

Rua Paschoal Marmo, 1888. Jardim Nova Itália. Limeira São Paulo - Brasil. ricardofesti@gmail.com

*** Universidade Estadual Paulista (Unicamp). Departamento de Sociologia.

Rua Cora Coralina, 100. Cidade Universitária. Cep: 13083896. Campinas - São Paulo - Brasil. fquerido@unicamp.br

${ }^{1}$ Encontre-se em preparação uma coletânea sobre a obra e a trajetória de Michael Löwy, a ser publicada em inglês
}

É tarefa inglória tentar oferecer uma síntese de seu labor intelectual. Após muitas décadas de intensa atividade, Löwy se revela como um dos mais importantes cientistas sociais em atividade, brindando-nos com uma obra multifacetada e, por isso mesmo, reveladora de um autor que, pela sua capacidade analítica e pelos conteúdos apresentados, situa-se na contramão da tendência crescente à especialização do trabalho acadêmico, além de contraditar, sempre com alto rigor reflexivo, tantos modismos que pautaram (e ainda pautam) a sociologia da cultura ao longo desse vasto período (Löwy, 2014; Querido, 2016; Roso, 2018).

Michael Löwy é um intelectual em seu sentido mais profundo. Sólido, navega em vastíssima gama de temáticas que abrangem a teoria social e as trajetórias intelectuais de autores como Marx, Lukács, Walter Benjamin, Weber, sempre buscando oferecer traços desses (e de tantos outros) autores ainda "desconhecidos" ou não suficientemente destacados. Contra

pela editora Brill, da Inglaterra, sob organização de Enzo Traverso e Darren Roso. Destaca-se ainda o vasto interesse por Löwy em diversos países da América Latina. 
tantas leituras que contrapõem frontalmente Marx e Weber, Löwy nos desconcerta demonstrando suas afinidades eletivas (Löwy, 2014). Há momentos de sua análise que, ao citá-los, antes de apresentar a fonte, o leitor fica sem saber quem é o real autor do fragmento por ele selecionado, tal é a similitude apresentada. Estudioso em profundidade incomum do jovem Lukács, encontrou, na verve de Trotsky, as decisivas contribuições para o desenvolvimento de sua concepção transformadora e libertária. De novo, rompia barreiras e tabus. ${ }^{2}$

Em seus estudos na teoria política, dialoga intensa e generosamente com os vários socialismos, os distintos comunismos e os diferenciados movimentos anarquistas e libertários, sempre procurando acentuar e destacar mais argutamente as aproximações e afinidades existentes entre eles, menos do que as tensões e diferenciações que não lhe parecem essenciais, sem, entretanto, omitir os momentos de ásperas confrontações. Foi exatamente o que fez recentemente, ao explorar os encontros e desencontros entre comunistas e libertários, provocando reflexões incomuns entre essas variantes que, muitas vezes, se aproximaram (como na criação da Associação Internacional dos Trabalhadores em 1864) e que, tantas vezes, também dissentiram tão fortemente œ (Löwy, 2016).

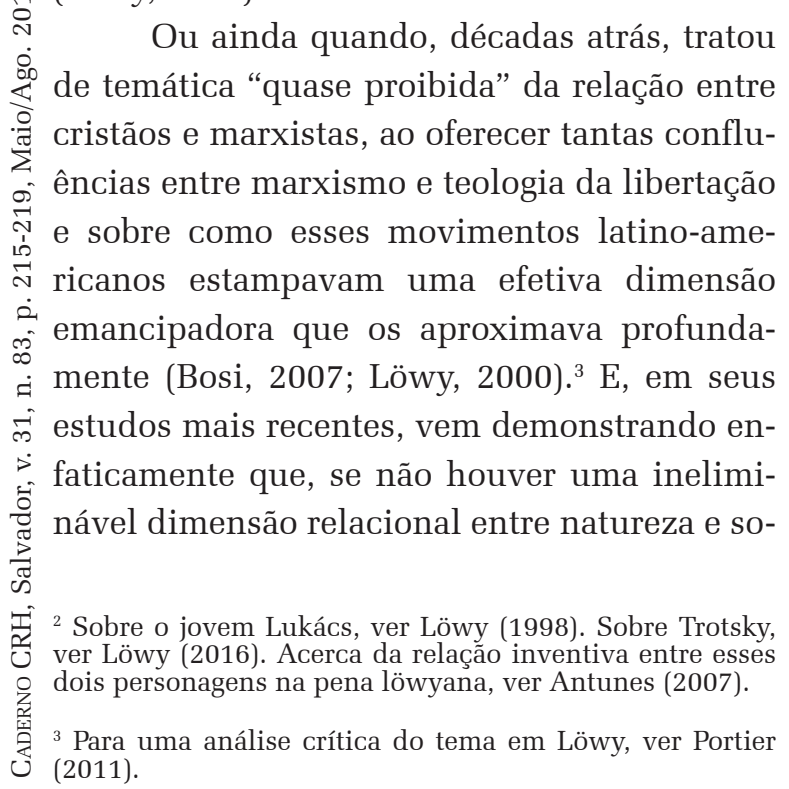

cialismo (o ecossocialismo), não haverá futuro plausível para a humanidade (Löwy, 2005a).

Explorou intensamente o tema do romantismo, das utopias, do messianismo, do marxismo latino-americano, sempre dotado de uma erudição enciclopédica, digna dos grandes pensadores (Löwy; Sayre, 2015). ${ }^{4}$ Brindou-nos com estudos sobre o surrealismo, escreveu ensaios saborosos sobre Kafka, enfim, é quase interminável a atividade intelectual desse sociólogo herético (Löwy, 2002). ${ }^{5}$

Combinando, como poucos, alta densidade teórica, exalando generosidade e pluralidade incomuns, mirando sempre outro horizonte societal - tendo como ponto de partida de sua conhecida atividade política o marxismo de Trotsky, como já indicamos anteriormente, mas se concebendo também como herdeiro direto de Rosa Luxemburgo -, Löwy descortina temas e redescobre objetos a cada novo estudo. No quadro do pensamento crítico contemporâneo, Löwy ocupa, assim, uma posição singular, que lhe confere a possibilidade de se posicionar no entrecruzamento de posições que inicialmente pareciam distantes, mas que, no enfrentamento a adversários comuns, acabaram por se aproximar (Azria, 2011; Delecroix, 2011). ${ }^{6}$

Oferecer traços e elementos decisivos da obra e da trajetória polissêmicas de Michael Löwy é o principal objetivo deste Dossiê. Como peças de um mosaico difícil de ser completamente preenchido, dadas a proporção e a amplitude de sua obra, os artigos aqui reunidos compõem, juntos, um quadro significativo - ainda que incompleto - do percurso intelectual de Löwy. Assinados por alguns dos maiores conhecedores e interlocutores dessa vasta obra, no Brasil e no estrangeiro, os artigos deste dossiê versam sobre aspectos e períodos variados da obra e do itinerário do autor, desde

\footnotetext{
${ }^{4}$ A propósito das utopias, ver Löwy (1989).

${ }^{5}$ Sobre Kafka, ver Löwy (2005b).

${ }^{6}$ Sobre os “dilemas” dessa posição utópico-anticapitalista,
} ver Querido (2017). 
sua primeira incursão na nascente sociologia do trabalho no Brasil, até seus estudos mais recentes sobre o ecossocialismo, passando por suas análises de autores importantes da tradição marxista (como Lukács e Mariátegui), pelos fundadores do pensamento social moderno (Marx e Weber), pelo intenso diálogo crítico com os mais distintos movimentos de emancipação, como o anarquismo, e o socialismo, percurso que possibilitou sua sólida, cosmopolita e internacionalista formação intelectual.

Em seus objetivos mais específicos, os artigos trazem à tona uma figura intelectual cuja exitosa carreira acadêmica - tendo galgado a condição de diretor de pesquisas do prestigioso Centre Nationale de la Recherche Scientifique (CNRS), onde se aposentou - jamais amenizou o seu compromisso com a ação por outro mundo possível e humanamente necessário. Em Löwy, uma coisa não vai sem a outra, o que não significa uma simples indistinção entre as temporalidades específicas do trabalho intelectual e da atividade política, mas sim a vigência de uma cuidadosa e mediada articulação entre essas esferas que pautaram sua vida intelectual, na qual a reflexão teórica sempre esteve atenta às suas inevitáveis - mesmo quando indiretas - ressonâncias políticas. Seu ponto de referência crítico-normativo, à luz do qual os temas são selecionados e abordados, permanece sempre como horizonte do trabalho intelectual, o que explica a crescente presença, em sua obra, da exigência benjaminiana de se escovar a contrapelo a história dominante, como se se tratasse de reforçar uma posição de resistência ao que se anuncia como irresistível, inevitável e, portanto, inquestionável (Löwy, 2005c).

Além de entrevista com o autor, realizada por Ricardo Festi (Unicamp), centrada (mas não apenas) em sua experiência nos primórdios da sociologia paulista do trabalho, no final dos anos 1950, publica-se aqui também tradução inédita de uma versão mais elaborada de um dos primeiros artigos de Michael Löwy, que apareceu originalmente no Brasil em 1962, na Revista Brasileira de Estudos Políticos (MG), em coautoria com Sarah Chucid (intitulado "Opiniões e atitudes de líderes sindicais metalúrgicos”). Nesse artigo, o jovem sociólogo expõe e analisa os resultados de pesquisa empírica realizada, ainda no período de graduação em Ciências Sociais, junto a alguns dirigentes sindicais de São Paulo, através de cujas respostas procurava apreender o nível de consciência de classe dos sindicalistas.

E é esse também o mote do artigo de Ricardo Festi: analisar de perto essa primeira fase da trajetória intelectual de Michael Löwy, com destaque exatamente para sua relação com a emergente sociologia do trabalho uspiana, no final da década de 1950, ou seja, antes de partir para a França em 1961, a fim de fazer o doutorado sobre o jovem Marx, com orientação de Lucien Goldmann. Trata-se de um momento pouco conhecido do percurso de Löwy, porém essa é uma experiência que deve ser levada em conta na formação e na trajetória do jovem sociólogo, que almejava testar "empiricamente" a consciência de classe dos trabalhadores sindicalizados à luz de um quadro conceitual inspirado na obra História e Consciência de Classe do jovem Lukács,

O ensaio de Enzo Traverso, proferido como conferência em Paris (França), arrisca algumas hipóteses em torno da trajetória intelectual de Michael Löwy, dos seus primeiros trabalhos sobre Marx, Lukács e Goldmann às suas reflexões mais recentes sobre Benjamin ou sobre o romantismo. Atualmente professor da Universidade de Cornell, nos EUA, Traverso aplica à análise do próprio intelectual franco-brasileiro o mesmo método que ele utilizara para compreender os mais diversos autores, defendendo a hipótese de que, embora tenha nascido no Brasil, Löwy pode ser visto como resultado de uma confluência e articulação entre duas tradições culturais e políticas do século XX: o judaísmo da Europa Central de antes da Schoah e a esquerda latino-americana posterior à revolução cubana.

Em chave mais circunscrita, Fabio M. 
Querido (Unicamp) analisa, em seu artigo, a obra e o itinerário intelectual de Michael Löwy nos seus primeiros desenvolvimentos, da formação em São Paulo à instalação definitiva em Paris, a partir do final da década de 1960, momento em que pôde dar vazão à dimensão cosmopolita e (ou) internacionalista fortemente presente no seu marxismo crítico, em contraposição a experiências mais "nacionais", como a participação no Seminário d'O Capital, em cuja pauta estava, além da leitura da obra magna de Marx, a tentativa de pensar os dilemas do país no qual viviam seus participantes, para o qual eles buscavam, de algum modo, uma saída possível. É nesse sentido que se pode entender a consolidação de Löwy, a partir de meados da década de 1970, como intelectual europeu (embora não eurocêntrico) de pleno direito, voltado para a análise de temas e autores "universais", por assim dizer, cujas obras dizem respeito aos problemas mais gerais do marxismo e do pensamento crítico internacional, mesmo quando a reflexão se dirige a algum país ou região (América Latina, especificamente).

O colombiano Renan Vega Cantor, por sua vez, professor da Universidade Nacional Pedagógica de Bogotá, situa, em seu texto, a importância da questão ecológica, ou melhor, ecossocialista, na obra mais recente de Michael Löwy, reatando suas afinidades eletivas com as temáticas do romantismo e da crítica do progresso tal qual foram trabalhadas pelo intelectual franco-brasileiro. Já os brasileiros Marco Aurélio Santana (UFRJ), Ricardo Musse (USP) e Ruy Braga (USP), esse último em coautoria com Deni Rubbo, doutorando em sociologia na USP, interpelam temas e autores específicos que compõem o repertório de Michael Löwy, com o olhar voltado para o tema do desenvolvimento desigual e combinado no âmbito contextual latino-americano.

Enquanto Marco Aurélio Santana analisa em pormenor a contribuição de Löwy para a sofisticação, operacionalidade e mesmo algumas dificuldades do conceito weberiano de afinidades eletivas, Ricardo Musse discorre sobre a leitura realizada pelo intelectual franco-brasileiro da obra e da trajetória do jovem Lukács, focando na forma como são mobilizadas, na interpretação em tela, as noções de anticapitalismo romântico e de reificação.

Por fim, Ruy Braga e Deni Rubbo destacam a relevância que a incorporação da obra do marxista peruano José Carlos Mariátegui teve no desenvolvimento da reflexão de Löwy, imunizando-o ainda mais contra as visões eurocêntricas do marxismo, mas, ao mesmo tempo, vacinando-o também contra os defensores da singularidade incomparável dos países latino-americanos. Para Löwy, como se vê também no artigo de Querido, os autores da periferia do capitalismo são importantes porque abordam de outro modo problemas candentes também no centro, e não porque encerram em si alguma marca específica irredutível.

No seu conjunto, o Dossiê aqui apresentado pretende, assim, oferecer ao leitor elementos fulcrais da obra e do itinerário de Michael Löwy, que, se não esgotam as tantas temáticas abordadas pelo autor, por certo apresentam sua rica dimensão polissêmica, o que torna possível compreender algumas das razões pelas quais o autor se transformou no intelectual que (ainda) é. Os textos podem ser entendidos, portanto, como fragmentos que apontam para uma totalidade cuja coerência interna jamais impediu um trabalho de atualização permanente, sem medo de confrontar "verdades" instituídas.

Não é por acaso que, nesse processo de atualização - do qual não estão ausentes as incursões pelo passado e pelo futuro -, torna-se possível flagrar a obra singular de um autor que, desde sempre, fez de si mesmo um representante intelectual dos de baixo. Para Löwy, afinal, diferentemente do que sustentara seu mestre "tardio", Max Weber, e em viva sintonia com seu outro mestre original, Karl Marx, a razão pode, sim, desde que não esconda os seus próprios pressupostos, chancelar os valores e as posições em disputa: entre os deuses em guerra há interesses e visões de mundo não 
apenas diferentes, mas humanamente antagônicos, e, nesse embate crucial, o nosso autor sempre soube - sem abdicar do rigor intelectual - o lado ao qual pertence.

Recebido para publicação em 03 de fevereiro de 2018 Aceito em 25 de abril de 2018

\section{REFERÊNCIAS}

ANTUNES, R. "Anotações sobre uma bela singularidade". In: JINKINGS, I.; PESCHANSKI, J. A. (Org.). As utopias de Michael Löwy: reflexões sobre um marxista insubordinado. São Paulo: Boitempo editorial, 2007. p. 19-24.

AZRIA, R. «Parcous intellectuel et itinéraire existentiel». In: DELECROIX, V.; DIANTEILL, E. Cartographie de l'utopie: l'œuvre indisciplinée de Michael Löwy. Paris: Sandre actes, 2011. p. 19-26.

BOSI, A. "Da esquerda cristã à teologia da libertação”. In: JINKINGS, I.; PESCHANSKI, J. A. (Org.). As utopias de Michael Löwy: reflexões sobre um marxista insubordinado. São Paulo: Boitempo editorial, 2007. p. 87-100.

DELECROIX, V. «Le temps romantique de Michael Löwy». In: DELECROIX, V.; DIANTEILL, E. Cartographie de l'utopie: l'œuvre indisciplinée de Michael Löwy. Paris: Sandre actes, 2011. p. 117-130.

LÖWY, M. Redenção e utopia: o judaísmo libertário na Europa central: um estudo de afinidade eletiva. São Paulo: Companhia das letras, 1989.

A evolução política de Lukács: 1909-1929. São Paulo: Cortez, 1998.
. A guerra dos deuses: religião e política na América Latina. Petrópolis: Vozes, 2000.

. A estrela da manhã: surrealismo e marxismo. Rio de Janeiro: Civilização brasileira, 2002.

. Ecologia e Socialismo. São Paulo: Cortez, 2005a.

. Franz Kafka - sonhador insubmisso. Rio de Janeiro: Azougue editorial, 2005b.

Walter Benjamin: aviso de incêndio: uma leitura das teses "sobre o conceito de história". São Paulo: Boitempo, 2005c.

A jaula de aço: Max Weber e o marxismo weberiano. Tradução de Mariana Echalar. São Paulo: Boitempo editorial, 2014.

A política do desenvolvimento desigual e combinado. São Paulo: Sundermann, 2016.

LÖWY, M.; SAYRE, R. Revolta e melancolia: o romantismo na contramão da modernidade. Tradução de Nair Fonseca. [S.l.: S.n.], 2015.

Afinidades revolucionárias: nossas estrelas vermelhas e negras: por uma solidariedade entre marxistas e libertários. Tradução de João Alexandre Peschansky e Nair Fonseca. São Paulo: Ed. Unesp, 2016.

QUERIDO, F. M. Michael Löwy: marxismo e crítica da modernidade. São Paulo: Boitempo, 2016.

"Dilemas do anticapitalismo contemporâneo: Michael Löwy e o marxismo libertário”. Outubro, n. 28, p. 81-99, 2017.

PORTIER, P. «Catholicisme et modernité dans l'oeuvre de Michael Löwy». In: DELECROIX, V.; DIANTEILL, E. Cartographie de l'utopie: l'œuvre indisciplinée de Michael Löwy. Paris: Sandre actes, 2011. p. 141-154.

ROSO, D. «Le marxisme de Michael Löwy, entre critique de la modernité et projet écosocialiste». Contretemps web: revue de critique communiste, 22 mars 2018. Disponível em: <http://www.contretemps.eu/marxisme-michaellowy/ $\geq$. Acesso em: 9 jun. 2018.

Ricardo Antunes - Professor Titular de Sociologia no Instituto de Filosofia e Ciências Humanas da UNICAMP. Professor convidado da Universidade Ca’Foscari de Veneza/Itália do Master sul Immigrazione, Fenomeni Migratori e Trasformazioni Sociali da mesma Universidade, sendo também Membro do Comitê Científico deste curso. Recebeu o Prêmio Zeferino Vaz da Unicamp (2003), a Cátedra Florestan Fernandes da CLACSO (2002) e a Medalha (Comenda) do Tribunal Superior do Trabalho (TST) (2013). Coordena o Grupo de Pesquisa Mundo do Trabalho e suas Metamorfoses (GPTM). Temas de interesse: sociologia do trabalho; teoria social; ontologia do ser social; nova morfologia do trabalho; trabalho e centralidade; classe trabalhadora; ação e consciência; sindicalismo e movimento operário. Publicações recentes: O Privilégio da Servidão (Boitempo, 2018); The Meanings of Work (Leiden/Boston: Brill/HM Book Series/FAPESP, 2013); Il lavoro e i sui sensi (Milão, Punto Rosso, 2016); Addio al lavoro? (Venezia, Edizione Ca'Foscari, 2015); The Meaning of Work (Delhi, Aakar Books, 2014).

Ricardo Festi - Doutorando em sociologia pela Universidade Estadual de Campinas, com estágio de estudos na EHESS (Paris). Professor de sociologia no COTIL-UNICAMP. Publicações recentes: "A Instrumentalização da Subjetividade no Trabalho pelo Capital”, Educação e sociedade, v. 37, p. 913-916, 2016; e "Terrorismo jihadista e kamikazes humanos: uma difícil questão para a contemporaneidade", Mediações - Revista de Ciências Sociais, v. 21, p. 386, 2016.

Fábio Querido - Professor do Departamento e do Programa de Pós-Graduação em Sociologia da UNICAMP. Tem experiência nas áreas de Teoria Sociológica, Pensamento Social e Político e Sociologia da Cultura. Trabalha particularmente com os seguintes temas: teoria e pensamento social, intelectuais, marxismo, crítica da modernidade; e com os seguintes autores: Michael Löwy, Walter Benjamin, Daniel Bensaïd, Roberto Schwarz, dentre outros. Publicações recentes: Michael Löwy - marxismo e crítica da modernidade (Boitempo Editorial/Fapesp, 2016), e de artigos diversos publicados em revistas nacionais e internacionais. 
